\title{
Determining the need for issue linkages in multilateral trade negotiations Bernard M. Hoekman
}

In multilateral trade negotiations (MTNs) held under the auspices of the General Agreement on Tariffs and Trade (GATT), trade-offs usually are made within the issue-areas that are on the agenda. ${ }^{1}$ However, the scope for within-issue trade-offs (linkages) is not always sufficient to achieve an agreement. In that case, negotiators need to be willing and able to investigate the feasibility of cross-issue linkages, since in principle these will increase both the scope for mutually beneficial agreements and the potential gains from trade. By explicitly recognizing the constraints embodied in the status quo and investigating the possibility of making linkages across issues, negotiators may be able to reach agreements whose outcomes are more beneficial for all concerned.

While cross-issue linkages are made in MTNs, in practice they tend to be forged in the closing stage of negotiations, apparently often without much aid in terms of prior substantive analysis of the possible options. To my

The research and writing of this article were carried out at the Institute for Public Policy Studies, University of Michigan, Ann Arbor. The work was supported in part by a grant from the Ford Foundation for a program of research on international trade policy. The views expressed are my own. I am grateful to the government officials in Washington, D.C., and Geneva who provided me with relevant documents and allowed me to interview them in November and December 1987. I also thank Paul Courant, Alan Deardorff, John H. Jackson, and Robert M. Stern for their advice. Detailed comments and suggestions by Stephen Krasner and two anonymous referees of International Organization greatly improved the article.

1. Seven rounds of negotiations have been completed to date. The last round was the Tokyo Round, which was concluded in 1979. An eighth round, the Uruguay Round, was launched in August 1986 and is still in progress. For information on the Tokyo Round, see Leslie Glick, Multilateral Trade Negotiations: World Trade After the Tokyo Round (Totowa, N.J.: Rowman \& Allanheld, 1984); and Gilbert Winham, International Trade and the Tokyo Round Negotiation (Princeton, N.J.: Princeton University Press, 1986). For information on the Uruguay Round, see C. Michael Aho and Jonathan D. Aronson, Trade Talks: America Better Listen! (New York: Council on Foreign Relations, 1985); J. Michael Finger and A. Olechowski, eds., The Uruguay Round: A Handbook for the Multilateral Trade Negotiations (Washington, D.C.: World Bank, 1987); and Gary Hufbauer and Jeffrey Schott, Trading for Growth: The Next Round of Trade Negotiations (Washington, D.C.: Institute for International Economics, 1985).

International Organization 43, 4, Autumn 1989

(C) 1989 by the World Peace Foundation and the Massachusetts Institute of Technology 
knowledge, formal analytic input in the negotiation process is usually limited to quantitative modeling efforts that estimate the possible effects of various options on variables such as welfare, net exports, and employment. ${ }^{2}$ Increasingly, however, trade negotiations concern nontariff measures (NTMs) for which quantification is often impossible. Although less precise, a qualitative approach may then be the only feasible one.

The objective of this article is to develop an analytic framework that can be used by policymakers and analysts to determine the need for cross-issue linkages. The first section of the article discusses some of the constraints imposed on and by negotiators in MTNs. The second focuses on quantitative analytic approaches, while the third proposes a qualitative one. The fourth section applies the qualitative methodology to the issue of developing multilateral safeguards to protect domestic industries from problems related to increases in imports, an important issue that was discussed at length in the Tokyo Round negotiations and appears again on the Uruguay Round agenda.

\section{Background: trade negotiations and the role of issue linkages}

The raison d'être of GATT and the negotiations held under its auspices is to help nations agree to behave in a cooperative manner that ensures an outcome which is beneficial to all parties and more acceptable than if each had acted independently. Outcomes associated with noncooperative behavior are generally inefficient in that there are likely to exist alternatives that can improve things for all concerned. An agreement to negotiate implies a recognition of the existence of potential gains from cooperation. ${ }^{3}$

To a large extent, MTNs are equivalent to barter. That is, trades occur in a setting in which there is no generally accepted medium of exchange (money). Barter is possible when there are enforced property rights, when marginal valuations of goods differ, and when potential transactors can meet

2. There are numerous studies estimating the effects of various types of liberalization of tariffs and nontariff measures, both globally and by sector. Agriculture, in particular, has been the focus of an immense amount of research. Models have been based on partial or general equilibrium approaches. For a recent study of Uruguay Round liberalization options, see Alan V. Deardorff and Robert M. Stern, "Alternative Scenarios for Trade Liberalization," Discussion Paper no. 217, Research Seminar in International Economics, University of Michigan, Ann Arbor, July 1988. Studies on the Tokyo Round include the following: William R. Cline et al., Trade Negotiations in the Tokyo Round (Washington, D.C.: Brookings Institution, 1977); Alan V. Deardorff and Robert M. Stern, The Michigan Model of Production and Trade (Cambridge, Mass.: MIT Press, 1986); and United Nations Conference on Trade and Development, Assessment of the Tokyo Round of Multilateral Trade Negotiations (New York: United Nations, 1982).

3. The outcome of noncooperative behavior is often assumed to be a Nash equilibrium. Here, it is assumed that given the actions of all other nations, each nation will act to maximize its own objectives. Prisoner's dilemma is a model of such a situation. Cooperative outcomes are usually defined to be Pareto-optimal-that is, no party can gain without another party losing. 
each other. As any good introductory textbook of economics explains, however, barter is inefficient. Indeed, its inefficiency is one of the historical reasons for the creation of money. But in international relations there is usually no "money," and nations are therefore forced to barter. Bartering entails three kinds of inefficiencies: (1) the "market" (total supply) may not offer any goods that a trader is interested in obtaining; (2) a trader who has something another wants may not be interested in what the other has to offer but may be interested in the goods of a third party; and (3) it may not be possible to equate marginal valuations of the various goods. If the first possibility occurs, trade will not be possible and the status quo will be maintained. If the second possibility occurs, trade will only be feasible if the third party can be found and happens to be interested in the first party's goods, so that each trader has something that another wants. In this context, economists sometimes speak of the need for a "double coincidence of wants." Even if this condition is met, trade will only occur if marginal valuations can be equated. This is the third potential problem mentioned above. If it cannot be solved-for example, because goods are "lumpy" or indivisiblethen trade will not take place.

All of these problems or inefficiencies affect MTNs, since an MTN is nothing more than a marketplace where potential traders meet. To ensure that the traders are rewarded for participating (that is, that there is something to trade), a great deal of care is taken to establish an agenda that includes some topics or issues of interest for each of the parties that are willing to trade. ${ }^{4}$ Trade can then occur both within and across issues. Trade within an issue is exemplified by tariff negotiations in which countries make bids and offers on the levels of specific tariffs. ${ }^{5}$ In principle, if there are enough issues, cross-issue trade may allow agreement if within-issue trade proves insufficient to generate an improvement over the status quo for all concerned. Thus, for example, agreement on a definition of subsidies could be made contingent on agreement that stricter rules be imposed on emergency protection against imports. In terms of the negotiating process, linkages play a fundamental role in fostering agreement because they allow side-payments to be made.

The problem facing negotiators is generally twofold: when and what to link. The question of when to link is a function of the type of situation confronting the negotiator. If negotiations reach a point at which there are insufficient mutual gains to be achieved by cooperating within a given issuearea - that is, the gains are distributed too asymmetrically - cross-issue link-

4. Prior to and during an MTN, the national authorities, industries, and bureaucracies will be engaged in a domestic negotiation to determine interests, priorities, and possible trade-offs. It is this work that leads to the establishment of the agenda.

5 . In the case of tariff negotiations, barter is less of a constraint, since the effect of trades can be expressed in quantitative terms. However, there is still no generally accepted medium of exchange. 
age quickly becomes necessary. ${ }^{6}$ The question of what to link is isomorphic to the question of what to trade. The conditions necessary for fruitful issue linkage (for gains to be made through trade) are then immediately obvious: the marginal valuations of different issues must vary across nations, and the proposed linkages (trades) must result in outcomes that make all parties better off than the status quo. ${ }^{7}$ This assumes that there are no credible threat strategies-that is, if no agreement is reached, the status quo will be maintained. But this does not have to be the case. If credible threat strategies are employed, it is, of course, crucial to incorporate these into the analysis, as discussed below.

Historically, GATT Contracting Parties have tended to constrain themselves to trade-offs within issue-areas, owing to their practice of establishing separate negotiating "groups" for each issue.$^{8}$ As a result, any attempts to link across issues have generally been made only at the end of a negotiation, since it is only then that positions on issues are completely mapped out and the need for linkage becomes clear. However, trade-offs at this point tend to be made at a high political level, under substantial time pressure, and with little (if any) analytic input. In addition, linkage at this point tends to focus more on achieving a balance of gains and concessions (reciprocity) than on increasing potential joint gains. ${ }^{9}$

Balancing gains and concessions is relatively easy in the case of tariff negotiations, but it becomes much more difficult when the subject of negotiation is broadened to include NTMs, whose effects may be difficult to quantify. The problem is twofold: (1) while tariffs can be changed incre-

6. See Robert Tollison and Thomas Willett, "An Economic Theory of Mutually Advantageous Issue Linkages in International Negotiations," International Organization 33 (Autumn 1979), pp. 425-49; and James K. Sebenius, "Negotiation Arithmetic: Adding and Subtracting Issues and Parties," International Organization 37 (Spring 1983), pp. 281-316. Note that even if crossissue linkage is not necessary to achieve agreement, it may be fruitful in terms of increasing mutual gains.

7. As noted by Tollison and Willett, this requires that agents agree on the nature of the set of Pareto-optimal outcomes. This will be a function of the availability of information. The less information agents have about the issues, the "fuzzier" the Pareto-optimal set will be. See Robert D. Tollison and Thomas D. Willett, "Institutional Mechanisms for Dealing with International Externalities: A Public Choice Perspective," in Ryan Amacher and Richard Sweeney, eds., The Law of the Sea: U.S. Interest and Alternatives (Washington, D.C.: American Enterprise Institute, 1976), pp. 97-100.

8. This is also the case in the ongoing Uruguay Round, which was launched in 1986 by a declaration that established fourteen subjects for negotiation. The following procedural constraint was imposed: "Balanced concessions should be sought within broad trading areas and subjects to be negotiated in order to avoid unwarranted cross-sectoral demands." See Finger and Olechowski, The Uruguay Round, p. 237; emphasis added.

9. From a practical political perspective, the term "reciprocity" has traditionally been used in the sense of a balance of gains and concessions. In both the U.S. and Economic Community (EC) context, reciprocity is currently used in the sense of attainment of a "level playing field" and equivalent market access. In this article, I follow the more traditional interpretation. For more information on various interpretations of the term, see Robert O. Keohane, "Reciprocity in International Relations," International Organization 40 (Winter 1986), pp. 1-27; and Alan L. Winters, "Reciprocity," in Finger and Olechowski, The Uruguay Round, pp. 45-51. 
mentally, NTMs tend to be "lumpy" or indivisible;" and (2) with NTMs, it is much more difficult to translate the value of issues and proposals into a common denominator. The general barter problems become more stringent when NTMs are involved, since it will be more difficult to make side-payments. Because policy issues are "lumpier" than tariffs, gains from trade become more difficult to realize.

In the case of NTM discussions, cross-issue linkages require explicit initiatives on the part of negotiators and policymakers. In practice, such initiatives occur relatively infrequently." Possible explanations for this are not difficult to find. From the perspective of a negotiator from a particular country, going beyond within-issue trade-offs in an attempt to maximize potential joint gains via cross-issue linkages is likely to bring about increased benefits for some domestic interest groups but losses for others. While this will be compensated by greater net gains for the country as a whole, the losers are likely to be more vocal about their losses than the gainers are about their gains, in large part because the latter are likely to be much more dispersed than the former. The implication is that cross-issue linkage can involve greater political difficulties for negotiators, who are often faced with the situation of having to "sell" the deal to domestic constituents without having the power to compensate potential losers. This is one of the reasons why reciprocity in the sense of obtaining a balance of gains and losses within an issue-area is often considered to be critical in MTNs. The problem of "selling" the deal to domestic constituents is then simplified.

Related to this is the fact that cross-issue linkages tend to be more transparent in negotiations regarding NTMs than in those regarding tariffs. The latter are often so complex that it is difficult to determine exactly what tradeoffs have been made. In addition, it is often possible to exempt specific industries or products in the case of tariff negotiations, while this is difficult in the case of NTM negotiations. In either case, however, other practical problems with attempting to achieve cross-issue linkages are that the balance attained in other issues may be upset and that this may lead to bureaucratic "turf" problems. Indeed, it is sometimes the case that negotiators are explicitly precluded from pursuing cross-issue linkages.

All of these difficulties could justify a hypothesis that policymakers are "rationally ignorant" about possibilities for increasing joint gains. ${ }^{12}$ However, this does not mean that improving on the status quo is impossible. Policymakers have many instruments at their disposal to compensate domestic losers. The point is that nations are engaged in a positive sum game. As long as there are potential joint gains, compensation problems should

10. In only a few cases can an NTM be converted into a tariff equivalent, such as the producer subsidy equivalent or the effective rate of assistance. The problem of quantification is discussed further in a subsequent section of this article.

11. As noted above, the Uruguay Round declaration appears to actively discourage crossissue linkage attempts.

12. I owe this term to an anonymous referee of International Organization. 
not be allowed to prohibit cross-issue linkages. Instead, these problems should be identified and dealt with by the appropriate policymakers. Greater transparency as to which parties gain and lose is required. Often the groups that may be affected negatively in the future are the ones currently benefiting from protection of some sort, and the question needs to be raised whether the benefits (rents) accruing to these groups are worth the costs to the nation. To a large extent, the problems inhibiting cross-issue linkages are the same ones that hamper trade liberalization. Thus, elements of a solution will be similar to those suggested in the literature on the political economy of protection. In particular, it is necessary that the costs of existing measures of protection be publicized more and that interim measures be put in place to lessen the adjustment burden if this protection is reduced. ${ }^{13}$

As noted previously, negotiators in MTNs do not have much scope to deal with compensation issues. For this reason, issue linkage is likely to require the introduction of high-ranking officials into the negotiation process. Not only would these officials need to be able to deal with the compensation problems associated with cross-issue linkages, but they would also have to explore with their counterparts where linkages are required and which particular trade-offs seem feasible. ${ }^{14}$ So as not to unnecessarily upset attained agreements on issues where interests have been balanced, linkage efforts should focus especially on issues where no agreement seems feasible.

A precondition for all of this is that the need for cross-issue linkage exists. Thus, there is a need for analytic methods (1) to determine ex ante the potential need for cross-issue linkage and (2) to identify specific linkages that could lead to an outcome which is beneficial to all parties involved in the negotiations. How this could be done is the subject of the next two sections, which focus on quantitative and qualitative procedures.

\section{Modeling MTNs: quantitative approaches}

Two related quantitative approaches have been proposed in the literature focusing on MTNs. The first calculates the effects of various possible agreements on variables such as net trade, employment, and welfare and will thus be referred to as an economic approach. ${ }^{15}$ The second is a game-theoretic approach that focuses on the interaction of players and, in particular, on the

13. For a detailed discussion of these matters, see Samuel Laird and Gary Sampson, "Case for Evaluating Protection in an Economywide Perspective," The World Economy 10 (June 1987), pp. 177-92; and Jagdish Bhagwati, Protectionism (Cambridge, Mass.: MIT Press, 1988).

14. To some extent, this is already done; see Winham, International Trade, p. 66. However, while the focus of the newcomers is often on deadlocked issues, cross-issue linkages are rarely pursued.

15. See, for example, Cline et al., Trade Negotiations; Deardorff and Stern, The Michigan Model; United Nations Conference on Trade and Development, Assessment of the Tokyo Round; and John Whalley, Trade Liberalization Among Major World Trading Areas (Cambridge, Mass.: MIT Press, 1985). 
distribution of payoffs associated with various solutions (equilibriums) to the MTN "game." 16 The general procedure in both approaches is to specify an objective function and to compare proposals in relation to the status quo by calculating payoffs. ${ }^{17}$ The feasibility of this depends on the type of issue that is being negotiated.

With the economic approach, it may be relatively easy to quantify the effects of various proposals if negotiations focus on existing levels of protection. Often, however, what is being negotiated are NTMs or contingent trade policy measures. To analyze the effect of altering NTMs, it is necessary to have information about (estimates of) tariff equivalents of the relevant instruments, and this information is often difficult to obtain. If what is being discussed are rules relating to contingent actions, it will be necessary to analyze and compare the effects of differing rules of behavior that will be applied only under specific circumstances. Although a major beneficial effect of agreeing to a rule is a reduction in uncertainty for traders, the economic impact of following the rule is often impossible to quantify. ${ }^{18}$

The economic approach assumes that the negotiators' objectives can be captured adequately by the particular variable or variables chosen, but it is often impossible to express all considerations in terms of economic variables alone. Thus, although this procedure is well suited for an ex post economic analysis of the results of a negotiation, it will be less relevant if the negotiator is interested in determining the scope for agreement ex ante. ${ }^{19}$

In game theory analyses, both noncooperative and cooperative game approaches have been used. Noncooperative approaches assume that each nation acts to maximize its payoffs subject to the actions of all others. Cooperative approaches assume that participants act to maximize joint payoffs (the value of the game) and focus on optimal ways to distribute the

16. See, for example, Deborah L. Allen, "Tariff Games," in S. J. Brams, A. Schotter, and G. Schwoediauer, eds., Applied Game Theory (Wuerzburg: Physica-Verlag, 1979), pp. 270-84; Robert E. Baldwin and Richard N. Clarke, "Game Modeling the Tokyo Round of Tariff Negotiations," Working Paper no. 1588, National Bureau of Economic Research, Cambridge, Mass., March 1985; and Kenneth S. Chan, "The International Negotiation Game: Some Evidence from the Tokyo Round," Review of Economics and Statistics 67 (Spring 1985), pp. 456-64.

17. A payoff should be understood to comprise the realization of the objective function for a given proposal or outcome.

18. The problem here is the same one that arises if an analyst desires to quantify the effects of the Tokyo Round codes of conduct: many of the effects are inherently unquantifiable. See Robert Stern, John H. Jackson, and Bernard Hoekman, Assessment of the GATT Codes of Conduct, Thames Essay no. 57, Trade Policy Research Centre (Aldershot, U.K.: Gower Press, forthcoming).

19. The empirical literature consists primarily of analyses of tariff negotiations. Quantification in the case of tariffs is relatively easy because the difference between the method and degree of tariff reduction proposed by any nation can be measured and compared with that of the status quo. Theoretical approaches to modeling MTNs also tend to focus on tariff negotiations. For two examples and references to the literature, see Wolfgang Mayer, "Theoretical Considerations on Negotiated Tariff Adjustments," Oxford Economic Papers 33 (February 1981), pp. 135-53; and Raymond Riezman, "Tariff Retaliation from a Strategic Point of View," Southern Economic Journal 48 (January 1982), pp. 583-93. 
payoff (equilibriums or solutions). Cooperative or "value-type" solutions are based on different sets of "reasonable" axioms (assumptions) and are usually rather ad hoc ways of selecting specific Pareto-optimal outcomes. ${ }^{20}$ When analysts calculate value solutions, it is implicit that agreement will be by consensus, which has traditionally been the GATT practice. ${ }^{21}$

While the value solutions described in the literature are normative, they are useful because actual outcomes can be compared with those predicted by various solution concepts. This is an interesting exercise, since it allows some insight to be gained into the relative importance of distributive versus efficiency considerations in determining actual outcomes of MTNs. In an investigation of the tariff proposals made during the Tokyo Round, Kenneth Chan concluded that the proposal finally chosen (the Swiss proposal) is best explained by solution procedures that emphasize "fairness" considerations. ${ }^{22}$ That is, he found that the Swiss proposal distributed the gains from liberalization across players in proportion to the weight (contribution) of each player. Solutions based on efficiency - that is, the maximization of the sum of gains across countries, independent of the distribution-did not work well. A similar result was found by Deborah Allen for the Kennedy Round. ${ }^{23}$ These findings are quite intuitive, since they reflect the "reciprocity approach" that underlies MTNs. To the extent that trading (linking) of issues does not occur, outcomes can be expected to reward players proportionately. ${ }^{24}$

A problem with the existing quantitative literature is that there is no focus on the scope for an agreement. This is largely due to the fact that analyses are ex post. Thus, no account is taken of how an agreement is reached, what the role of threat strategies (if any) was, and so forth. This does not mean, of course, that it is impossible to address this issue using a quantitative approach. The problem, however, is the need for quantification of payoffs. The use of existing quantitative approaches is generally only feasible if analyses focus on successfully concluded tariff negotiations. Tariffs are only

20. Cooperative game equilibriums for MTNs have been calculated by Allen in "Tariff Games," Baldwin and Clarke in "Game Modeling," and Chan in "The International Negotiation Game."

21. In the Tokyo Round, a number of side-agreements (codes) with limited membership were negotiated, implying that consensus no longer can be taken as the norm. Although GATT formally requires that its members treat nations on an MFN basis, in practice some degree of discrimination occurs. See Stern, Jackson, and Hoekman, Assessment of the GATT Codes of Conduct.

22. Chan, "The International Negotiation Game."

23. Allen, "Tariff Games."

24. In "Game Modeling the Tokyo Round," Baldwin and Clarke note that while there are solution concepts that come close to predicting the solution actually chosen, in reality the Tokyo Round tariff negotiations had an outcome that was much inferior to the one that would have resulted from the application of the Swiss proposal. They argue that this was due to the large number of exceptions made in the final stage of the negotiations as countries attempted to achieve reciprocity and satisfy domestic interest groups. This led to a movement away from rather than toward the Pareto frontier. 
a small aspect of MTNs, however, and for many of the issues that currently are discussed, quantification of payoffs is not possible. In this case, since neither the economic nor the game-theoretic modeling approach can be used, an alternative approach is needed.

\section{Determining the scope for agreement: a qualitative approach}

In the discussion that follows, I assume that the subject of negotiation precludes quantification. In any MTN, issues can be considered to be exogenously given by the agenda. ${ }^{25}$ In practice, given the large number of GATT members (currently ninety-six), the first step of analysis is to determine which nations are the most important ones and which are "like-minded" on an issue. The latter requires a determination of each player's objective. In general, the three most important players are the European Community (EC), Japan, and the United States. Depending on the issue, they will be joined by other nations or blocs of nations. Developing countries often negotiate (implicitly) as a bloc. In general, all nations with equivalent positions on an issue can be regarded as one "player" for purposes of analysis. ${ }^{26}$ Determining the objectives per issue per nation usually will not be too difficult, since these are often well publicized. If necessary, interviews with the relevant policymakers should be undertaken to help determine objectives.

The next step is to construct a set of proposals that represent as parsimoniously as possible alternative solutions for each issue. For each issue to be analyzed, it is necessary to identify a minimal number of key attributes or elements that are controversial and need to be resolved. A set of possible proposals then can be constructed by varying the "realizations" of these elements. There is usually a sufficient amount of information available for this purpose. Indeed, there is sometimes too much information, and it is necessary to narrow things down. This is usually not a problem, since many aspects of a potential agreement on an issue are not controversial and thus will appear in all proposals. These can be ignored. Other aspects conceptually address the same issue and can be combined. ${ }^{27}$

The goal is to be able to compare the payoffs under alternative proposals

25. How these agenda items are determined is a separate question. While it is of great interest in itself, for the purposes of determining the scope that exists for agreement once the MTN has started, the agenda can be treated as given.

26. Throughout this article, the term "player" is used in this sense. It is not used to refer to a formal coalition.

27. While there is an element of "art" involved in the determination of the set of possible proposals, the procedure is less sensitive to subjective influences than might be thought. Participants in MTNs usually make clear what they perceive to be the problems on an issue. In cases in which a nation offers no explicit proposals for change, it is likely that the nation considers the status quo to be acceptable. Given a comprehensive analysis of the status quo, most analysts should end up identifying a similar universe of possibilities. 
with the payoff under the status quo. ${ }^{28}$ In doing this, the possibility for coalition formation must be taken into account. Coalition formation can be important if an agreement has to apply on a most-favored-nation (MFN) basis; it is, of course, necessary if nonsignatories are to be excluded from benefiting from the agreement (the non-MFN case). In the MFN case, coalition formation may help achieve an agreement. The point is that even though benefits of an agreement are "public," there might be incentives for at least a subset of nations to cooperate. ${ }^{29}$ Obviously, a need to determine "values" for all possible coalitions in an MTN would lead to difficulties. In the GATT context, however, there are some constraints on coalition formation. In particular, certain players must belong to a coalition for it to be viable. In practice, these players have been the EC, Japan, and the United States. They were members of all of the agreements negotiated during the Tokyo Round, and it is difficult to envision any major multilateral trade agreement that would exclude one of them. Imposing the constraint that these three players must belong to a coalition greatly simplifies the analysis because many coalitions will not be viable.

In general, a minimal condition for agreement to be possible in any case (including a case in which privileged groups or clubs can form) is that "individual rationality" constraints are met. This means that each player must benefit as much under the proposed agreement as under the status quo or, in cases in which there are credible threats, as much as if no agreement were reached. To determine whether these constraints are met, it is not necessary to be able to quantify payoffs precisely; all that is required is that alternatives be comparable to the status quo or no-agreement outcome. To see this, it is useful to characterize more concretely from a trade policy perspective the general problem facing a nation when negotiations focus on NTMs. Assume that any exporting nation faces two possible states of the world: one in which a "trade policy action" is taken against it by an importing nation and one in which nothing happens. If "action" occurs (if a measure that directly or indirectly affects trade flows is taken), it will follow a "rule," be it implicit or explicit. Presumably, if there is an agreement that applies to the policy area in question, the rules embodied in it will be followed. With this in mind, the exporting nation can then compare its current expected payoff under the

28. Alternatively, if use is made of credible threat strategies, payoffs must be compared to the no-agreement outcome.

29. For an analysis of when coalitions will form in cases in which it is impossible to exclude nonsignatories, see Mancur Olson, The Logic of Collective Action (Cambridge, Mass.: Harvard University Press, 1965); and Thomas Schelling, Micromotives of Macrobehavior (New York: W. W. Norton, 1978). A necessary condition is that the nations which are able to agree will benefit sufficiently so that free riding by the rest of the world does not endanger the agreement. In cases such as this, Olson refers to these nations as a "privileged" group; Schelling speaks of "k-groups," with " $k$ " being the minimal number of parties necessary for agreement to be feasible. Economists generally speak of "clubs," although usually in a context in which exclusion is possible. See Richard Cornes and Todd Sandler, The Theory of Externalities, Public Goods, and Club Goods (Cambridge, Mass.: Cambridge University Press, 1986). 
status quo rule with that under alternative rules. ${ }^{30}$ This approach is equally applicable to importing nations. Thus, the analyst can assume that the importer also faces two states of the world: one in which action is necessary and one in which it is not. In the case of an importing nation, the question then is what kind of rules it is willing to subject itself to ex ante.

This can be stated in slightly more formal language: each nation can be assumed to be attempting to maximize the expected value of its objective function, $\mathrm{W}$, or in a two-state world, $\max \mathrm{W}=\pi \mathrm{U}_{\mathrm{j}}+(1-\pi) \mathrm{U}_{0}$, where $\mathrm{U}_{0}$ is the utility realized if no action occurs (or is necessary), $\pi$ is the probability of an action, $j$ indexes a possible rule, and $U_{j}$ is the utility given an action that follows the rule. ${ }^{31}$ The problem of a nation or bloc is then to choose a rule so as to maximize $U_{j}$, subject to the individual rationality constraint that $U_{j}>U_{n a}$, where $U_{n a}$ is the utility derived from the no-agreement outcome. ${ }^{32}$ This may reflect the status quo rules or procedures, or it may reflect payoffs in a case in which threat strategies are carried out. Thus, it is important to determine what $U_{n a}$ is per player per issue.

In most cases, comparison of various rules on a given issue relative to the status quo will be all that is needed. This is because threats, if carried out, are likely to lead to an outcome that is worse than the status quo for all concerned. If this is the case, any proposal ranked above the status quo for all participants will be an improvement in comparison to the threat outcome, the individual rationality constraints will have been met, and an agreement should be feasible. Even if proposals represent only a slight improvement over the status quo, there may still be substantial scope for agreement to occur because threats exist. On the other hand, if carrying out the threats will make a nation better off than under the status quo, comparisons must be made with the no-agreement (threat) outcome rather than the status quo. In these cases, the need for issue linkage is quite apparent, since without linkage it would be difficult to restrain a nation from carrying out its threats. Taking into account the existence of credible threat strategies is therefore important in terms of determining the scope for agreement.

If cardinal information were available, comparisons of payoffs would be straightforward and unambiguous. In practice, however, only ordinal information is available, and this is usually all that is required to compare alternatives to the no-agreement outcome. Of course, there may be difficulties in specific situations. For example, if outcomes associated with one policy option appear to be slightly better than those associated with another option but the policymakers are not really confident about this, a ranking of options

30. As noted previously, however, if threats exist, comparisons need to be made with the payoff associated with the no-agreement outcome.

31. The objective function and its attributes are left undetermined at this point, since they will depend on the issue at hand. An alternative objective might be the maximization of output or the minimization of political losses.

32. This implies that although $\pi$ will depend on many things, its determinants are not relevant in this connection. 
may not be possible. However, in such cases, the options are for practical purposes equivalent.

For an analyst to be able to evaluate proposals in terms of whether they are better or worse than the status quo for each player requires information on their preferences (objectives) and the weight they place on the elements or attributes characterizing the various possible proposals..$^{33}$ Often, much of the required information can be obtained from published sources. If there is some ambiguity, as there is likely to be, especially for new issues, it is necessary to communicate directly with the parties involved. This can be done formally by means of questionnaires or informally through interviews.

At this point, something needs to be said about strategic behavior, especially the misrepresentation of preferences and its implications for the analyst. Obviously, negotiators (acting on instructions from their capitals) will at times behave strategically. Thus, a distinction needs to be made between goals and tactics. Much of the actual negotiating that occurs is a function of tactics, and strategic behavior is likely to be rampant here. However, this is not of great concern, since what is fundamental to the analysis are the ultimate goals (objectives) of the relevant players. While strategic behavior remains possible and may lead to failure of the negotiations, the scope for misrepresentation of preferences is limited by the fact that the goals are often publicly debated and determined and are thus relatively clear. ${ }^{34}$

Given identification of the relevant players, possible proposals, and a comparison of the proposals in relation to the status quo, it is easy to determine the scope that exists for an agreement. Formation of a grand coalition (consensus) will be impossible if even one relevant player considers the outcome of a proposal to be less beneficial than the no-agreement outcome. What about the formation of privileged groups or clubs? For clubs to form, it is necessary that at least two players believe they will benefit more under a given proposal than under the status quo. ${ }^{35}$ In practice, whether players choose to form a club depends on the circumstances and, in particular, the extent to which the benefits to signatories outweigh any costs of free riding by nonsignatories. But even if benefits to signatories are large, this is only a necessary condition for an agreement to be feasible. It is not sufficient.

If the analysis of an MTN along the lines discussed above indicates that agreement is unlikely on certain issues, the next step is to determine if there

33. This information is a minimal requirement. If enough unambiguous information is available, it may be possible to rank order proposals. To do this, it is necessary to be able to determine the marginal effect of slight changes in the proposals. However, a complete rank ordering is not required to determine the scope for agreement.

34. That strategic behavior can lead to failure to agree is well known. For an analysis of the various ways in which this behavior can lead to a breakdown of discussions, see Howard Raiffa, The Art and Science of Negotiation (Cambridge, Mass.: Harvard University Press, 1982).

35. That is, if $U_{j}>U_{n a}$ for at least two players for the same $j$, a club could form. In the GATT context, however, a club will only be viable if the major trading nations or blocs are members of it. 
are any issues that can be linked. ${ }^{36}$ In general, for cross-issue linkage to be feasible, it is necessary that the major disagreeing players perceive their interests to be opposed on both issues and that the issues offer sufficient scope for trade-offs. A central problem is the difficulty of ensuring that the disagreeing players can find "linkable" issues on the agenda. ${ }^{37}$

For linkage to be manageable, nations need to form blocs on specific issues and then trade these issues as blocs. This applies especially if a consensus agreement is required but also applies if attempts are made to form a club. In a multilateral setting, nations with the same preferences on one issue are unlikely to all have the same preferences on another. Issues therefore need to be chosen carefully so that linkage will be feasible and fruitful. To determine which issues can be linked most fruitfully, it is necessary to rank the issues across nations in order of increasing relative importance. To maximize potential gains and thus the scope for agreement, each nation or bloc must be willing to give concessions on an issue it cares relatively little about in return for gains on an issue it cares relatively much about.

In the next section, the proposed qualitative approach is illustrated by focusing on an issue that has been on the agenda of the international trade policy community for a lengthy period of time: rules on emergency protection or safeguards.

\section{An application: the scope for agreement on safeguards}

Safeguards are actions taken to protect domestic import-competing industries from problems related to increases in imports ("market disruption," "import surges," and so on). Article XIX of GATT allows these actions to be taken when imports seriously harm domestic industries or threaten to do so. Measures of support under Article XIX are to be temporary and nondiscriminatory - that is, they are to apply to imports of all origin. Furthermore, affected exporters have the right to retaliate if compensation is not forthcoming or is deemed to be inadequate. ${ }^{38}$

In the last decade, safeguard actions increasingly have been taken through procedures and mechanisms that circumvent GATT. Voluntary export restraint (VER) agreements are a prominent example. ${ }^{39}$ One of the objectives

36. The same applies if there are no credible threat strategies and it appears likely that an agreement will improve on the status quo only marginally for one or more players.

37. In principle, of course, it is not necessary that issues all be on the agenda. If there were a requirement, theoretically it would limit potential gains, but it also might simplify things, since ensuring that many "linkable" issues are on the agenda would make it easier for the GATT Contracting Parties to agree on an agenda in the first place.

38. For recent works that focus on safeguards and emphasize the importance of the issue for the multilateral trading system, see Bernard Hoekman, "Services as a Quid Pro Quo for a Safeguards Code," The World Economy 11 (June 1988), pp. 203-15; and Gary Sampson, "Safeguards," in Finger and Olechowski, The Uruguay Round, pp. 143-52.

39. GATT, Review of Developments in the Trading System (Geneva: GATT, 1988). 
of the Uruguay Round is to develop an agreement on safeguards which will lead nations to stop applying "gray-area" measures such as VERs. Because the issue of safeguards was discussed at length in the Tokyo Round and because not much has changed since then, I will start by focusing on the last MTN.

\section{The Tokyo Round}

The major actors in the Tokyo Round have been the EC and the United States. Other participants have included Japan; industrialized countries that are small open economies (SOEs), such as Australia, Canada, New Zealand, Sweden, Norway, and Finland; the newly industrializing and other developing countries; and, finally, a number of countries with nonmarket economies. Among the participants, the Nordic countries had positions similar to those of the EC; the remaining SOEs and the nonmarket economies had positions similar to those of Japan; and the positions of the newly industrializing countries and other developing countries-that is, the less developed countries (LDCs) - were very close to each other. Thus, we may designate the four players as the $E C$, the $S O E$, the $L D C$, and the United States.

The EC's first published position with respect to the MTNs was drafted by the European Commission in April 1973. The initial viewpoint on safeguards was that Article XIX of GATT should be maintained but that alternative procedures for the discriminatory (selective) use of safeguards should be created and should include detailed provisions on the methods of their application and control. The Commission proposed surveillance by a quasijudicial tribunal of independent experts and suggested that rights to compensation be limited and that safeguards be linked to adjustment policies. ${ }^{40}$ Early in the Round, it became clear that selectivity and ex post surveillance were to be the primary objectives of the EC.

The objectives of the United States were reflected in the report of the Williams Commission, which concluded that the period of relief should be limited in duration and that relief should consist of a tariff increase if at all possible. If import quotas were to be used, they should be auctioned and the revenue should go to the importer's treasury. ${ }^{41}$ Strict preconditions should be satisfied before an action could be imposed. With respect to selectivity, the U.S. position was not clear. Although a preference for nondiscriminatory application of safeguards was expressed, this was not a burning issue. In practice, the United States was not opposed to consensual selectivity but wanted to block any move toward unilateral selectivity. ${ }^{42}$

40. Sidney Golt, The GATT Negotiations, 1973-1975: A Guide to the Issues (London: British-North American Committee, 1974).

41. U.S. Government, United States Policy in an Interdependent World (The Williams Commission Report) (Washington, D.C.: Government Printing Office, 1971), pp. 66-67.

42. See Sidney Golt, The GATT Negotiations, 1973-1979: A Guide to the Issues (London: British-North American Committee, 1978), p. 26; and Winham, International Trade, p. 199. 
Both $L D C$ and $S O E$ approached the issue of safeguards from the perspective of a target. The main goal of $S O E$ was the retention of the MFN application of Article XIX. The view was that safeguard actions should be multilateral, subject to stricter conditions, and placed under international surveillance and that adjustment should be linked to any safeguard action. Thus, nondiscrimination and satisfaction of preconditions for action were the major considerations for SOE. Most of the initial effort of $L D C$ focused on obtaining special and differential treatment in the application of Article $\mathrm{XIX}$ actions. The position of many developing countries was that safeguard measures taken by industrialized nations should not pertain to them unless GATT developed and pursued a procedure to determine that the exemption would be impractical or unwarranted. They also suggested that different standards should apply to developing countries with respect to the definition of concepts such as serious injury and cause of injury. ${ }^{43}$ However, if these countries were not granted exemption and the safeguards were to be applied to them, $L D C$ strongly favored nondiscriminatory application. $L D C$ also emphasized that the right to compensation should not to be limited in any fashion.

A typology of possible safeguard agreements is offered in Table 1. There are twenty-four possible types of agreement, each of which will determine a different payoff to the four players identified above. Possible agreements are characterized by different rules regarding compensation, preconditions (criteria for actions), and discrimination (selectivity). These three dimensions capture all of the stated objectives of the players, and they also cover most of the theoretical possibilities. Three types of remedies are also distinguished in Table 1: freely allocated quotas, tariffs or auctioned quotas, and domestic measures such as adjustment assistance or subsidies. I assume that if quotas are allocated freely, compensation does not have to be considered explicitly, since this occurs implicitly. This is not the case if tariffs are used or if quotas are auctioned and the revenue goes to the importer's treasury. ${ }^{44}$ Three possibilities with respect to the application of an agreement are distinguished: unilateral selectivity, consensual selectivity, and nondiscrimination. Note that nonborder measures (measures that do not directly affect trade flows across borders) will usually be nondiscriminatory in effect by definition.

Along analogous lines, it can be assumed that each player's utility function for safeguards $(U)$ has three components: compensation $(C)$, preconditions $(\mathrm{P})$, and selectivity $(\mathrm{S})$. Thus, $\mathrm{U}^{\mathrm{i}}=\mathrm{U}^{\mathrm{i}}(\mathrm{C}, \mathrm{P}, \mathrm{S})$, where $\mathrm{i}=E C, L D C, S O E$, or the United States. For SOE, $\mathrm{U}_{1}>0, \mathrm{U}_{2}>0$, and $\mathrm{U}_{3}<0$, where the subscript numbers denote the first partial derivative relative to the status quo magnitude of $\mathrm{C}, \mathrm{P}$, and $\mathrm{S}$. The $L D C$ position that developing countries

43. Glick, Multilateral Trade, p. 34.

44. My discussion of the Tokyo Round does not focus on domestic measures, since they did not play an important role in the negotiations. They may play a greater role in the Uruguay Round, however. 


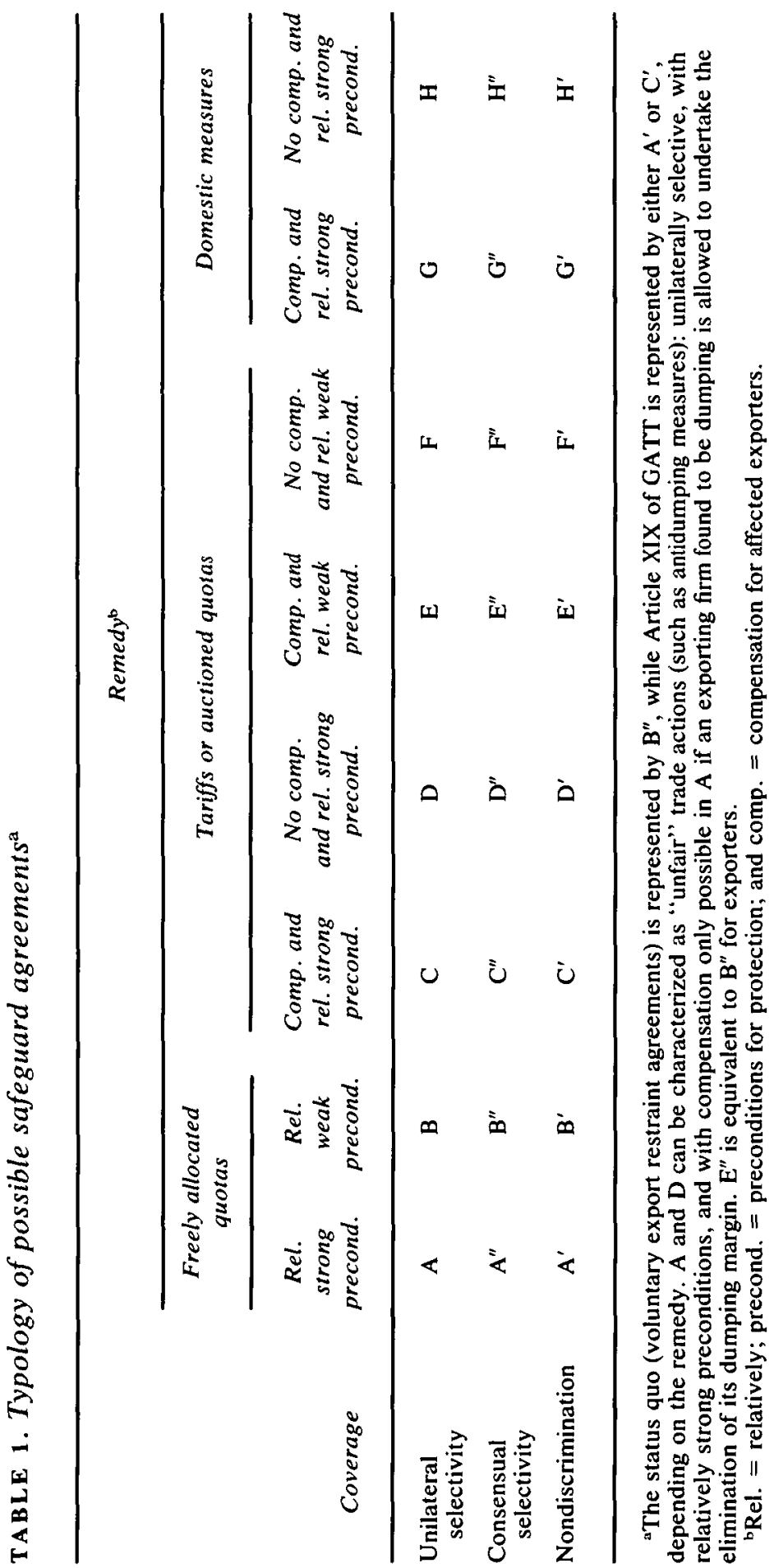


should be exempt from safeguard actions cannot be captured in the table, since it implies an indeterminacy as to a position on what rules should be applied. Nothing was offered by $L D C$ in order to obtain the desired exemption, and it became clear early in the negotiations that exemptions would not be granted. ${ }^{45}$ Thus, for the purposes of analysis of the options noted in Table 1, the position of $L D C$ will be taken to be a preference for nondiscrimination, even though this is "second best." This implies that the signs for the first partial derivative of $L D C$ will be the same as those for $S O E$.

For the United States and $E C$, the first partial derivatives are more difficult to sign, since importing and exporting interests have diverging preferences. I will assume that importing interests dominate, and therefore $U_{1}<0$ and $\mathrm{U}_{2}<0$ for both the United States and EC. However, $\mathrm{U}_{3}>0$ for $E C$, while $\mathrm{U}_{3}<0$ for the United States.

Based on the goals of the participants, it is clear that $S O E$ and $L D C$ had positions relatively close to that of the United States and that all of these positions were substantially at variance with that of $E C$. The primary objective of $E C$ was to block a nondiscrimination obligation, while that of $L D C$ and $S O E$ was to achieve nondiscrimination. As discussed above, $S O E$ put relatively greater emphasis on preconditions than did $L D C$ or $E C$, while $L D C$ put greater emphasis on compensation. ${ }^{46}$ For the United States, strict preconditions were considered to be fundamental. On the issue of selectivity, its major objective was to block unilaterally imposed selective measures.

The scope for a possible consensus agreement is determined by the number of proposals that are ranked above the no-agreement outcome by all of the players. In the context of the safeguard issue, the no-agreement outcome was equal to the status quo and consisted of VERs and related trade measures. There were no threat strategies that went beyond a proliferation of VERs. VERs are represented by $B^{\prime \prime}$ in Table 1 and are characterized by consensual selectivity, relatively weak preconditions, and rents accruing to exporters. Arguably, the status quo also includes procedures such as antidumping measures, which could be used de facto for safeguard purposes. ${ }^{47}$

45. That is, free riding of this sort was considered to be unacceptable by the major players. This is not surprising, since safeguard issues usually involve LDC exports. It is clear that within-issue trade-offs were useless for $L D C$ in attaining its goal. The question, then, is why the option of cross-issue trades was not pursued.

46. One explanation for this could be that LDCs have less faith in their ability to make full use of more stringent procedural requirements. Alternatively, they might not trust importing nations to adhere to them.

47. Dumping occurs when a firm sells a product abroad for less than it charges in its home market. In the absence of a home market (or in the presence of one that is too small), dumping occurs when the export price is below the fully allocated cost of production. If an exporting firm is found to be dumping and also to be causing injury to domestic import-competing firms, an antidumping duty can be levied. Alternatively, the exporter is often allowed to undertake the elimination of the dumping margin by raising its export supply price. Antidumping procedures can be used as substitutes for safeguards because criteria for receiving protection are less strict, and it is often not too difficult to show that dumping has occurred. See Bernard Hoekman and Michael Leidy, "Dumping, Antidumping and Emergency Protection," paper presented at the Research Seminar of the GATT Secretariat, Geneva, October 1988. 
In the context of Table 1, these actions can be represented by D, A, or B, depending on whether a unilaterally selective tariff is imposed (D) or an undertaking to eliminate the dumping margin is made by the affected exporter. If an undertaking is made, the relative stringency of preconditions that have to be satisfied will determine whether it is equivalent to A or B. However, in the discussion that follows, B" will be taken to represent the status quo, since VERs are the most prevalent substitute for GATT-conforming safeguard actions.

The question, then, is which proposals regarding quotas and tariffs were better than the status quo for each player? Alternatively, which proposals were worse than the status quo? For $L D C$, proposals worse than the status quo were $\mathrm{A}-\mathrm{F}$, which implied unilateral selectivity, and $\mathrm{F}^{\prime \prime}$ and $\mathrm{D}^{\prime \prime}$, which removed compensation. $F^{\prime \prime}$ was worse than the status quo because it would be equivalent to the VER regime but without the implicit compensation, while $\mathrm{D}^{\prime \prime}$ was worse than the status quo because on the margin $L D C$ attached greater weight to compensation than to preconditions. Proposal $\mathrm{E}^{\prime \prime}$ was equivalent to the status quo as far as exporters such as $L D C$ were concerned, and everything else with the possible exception of $F^{\prime}$ represented an improvement. ${ }^{48}$ For $S O E$, the same held true as for $L D C$, except that $\mathrm{D}^{\prime \prime}$ was considered better than the status quo because on the margin $S O E$ preferred more preconditions to more compensation. For the United States, proposals worse than the status quo were A-E, $E^{\prime \prime}, F^{\prime \prime}$, and $F^{\prime}$. In general, the United States was against unilateral selectivity. $E^{\prime \prime}$ was worse because it implied the same preconditions as under the status quo but at greater cost, while $\mathrm{F}^{\prime \prime}$ and $\mathrm{F}^{\prime}$ were worse because they implied no compensation and weak preconditions. $E C$ was the only player whose "bliss point" was close to the status quo. $E C$ preferred discrimination, no compensation, and relatively weak preconditions, and the status quo incorporated two out of three of these desiderata. The proposals better than the status quo included A, B, $\mathrm{D}, \mathrm{F}, \mathrm{D}^{\prime \prime}$, and $\mathrm{F}^{\prime \prime}$. $\mathrm{D}^{\prime \prime}$ was better because on the margin $E C$ preferred relatively more stringent preconditions over compensation.

Given that the only proposals which would improve on the status quo for $E C$ would be worse than the status quo for $L D C$, it is clear that little scope for a consensus agreement existed. What about clubs ${ }^{29}$ By assumption, only three possibilities existed for a potential privileged group: (1) the United States and $E C$; (2) the United States, EC, and $S O E$; and (3) the United States, $E C$, and $L D C$. It was concluded above that $E C$ preferred $\mathrm{A}, \mathrm{B}, \mathrm{D}$, $F, D^{\prime \prime}$, and $F^{\prime \prime}$ to the status quo $\left(B^{\prime \prime}\right)$ and that these would be worse than the

48. $\mathrm{F}^{\prime}$ could be worse if the benefits of nondiscrimination were outweighed by the costs associated with losing compensation and having relatively weak preconditions.

49. There are three possibilities: (1) a club forms, and the agreed safeguard rules are applied on a non-MFN basis; (2) a club forms, and the agreed safeguard rules are applied on an MFN basis; and (3) the potential for a club exists, but agreement is impossible because of the MFN constraint. In the third case, free riding is presumably considered to be unacceptable to the potential club members. 
status quo for $L D C$. However, $\mathrm{D}^{\prime \prime}$ was preferred to the status quo by three players: $S O E$, the United States, and EC. Thus, a privileged group could have formed on the basis of this preference. There are several possible explanations for the fact that it did not form. First, the MFN requirement of GATT was felt to be a binding constraint. Second, D" was only marginally better than $\mathrm{B}^{\prime \prime}$ for SOE. Third, the $\mathrm{D}^{\prime \prime}$ proposal was similar to A and D procedures, and since these procedures already exist, they may be viewed as a stronger version of $\mathrm{D}^{\prime \prime}$. Note also that $L D C, S O E$, and the United States had other proposals in common that they would have preferred to $\mathrm{D}^{\prime \prime}$. Given the options, $S O E$ and $L D C$ preferred an agreement incorporating nondiscrimination, relatively strong preconditions, and compensation-that is, $\mathrm{A}^{\prime}$ or $\mathrm{C}^{\prime}$. The United States preferred an agreement incorporating relatively strong preconditions, nondiscrimination, and a tariff remedy - that is, $\mathrm{C}^{\prime}$ or $\mathrm{D}^{\prime}$, depending on its stance on compensation. ${ }^{50}$ The goal of SOE, LDC, and the United States might then have been to persuade $E C$ to accept a proposal along the lines of $A^{\prime}$ or $C^{\prime}$. This, of course, would have required linkage of issues. As noted earlier, linkage would also have been necessary for $L D C$ to attain its most preferred option (an exemption). The obvious question, then, is why no linkages were attempted.

Although there is no definitive answer to this question, one hypothesis is that the policymakers were "rationally ignorant," as discussed above. Another is that there was insufficient awareness of the scope for making tradeoffs across issues. Potential linkages certainly existed, examples including concessions by $L D C$ on import licensing, subsidies, or government procurement. From a policy perspective, the interesting question is whether there have been any subsequent changes that will allow for an agreement to emerge without cross-issue linkages in the ongoing Uruguay Round. ${ }^{51}$

\section{The Uruguay Round}

While there were four players or blocs in the Tokyo Round, there are presently at least six players in the Uruguay Round negotiations on safeguards. The United States, the EC, and Japan should now all be regarded as separate players. Australia, Hong Kong, South Korea, New Zealand, and Singapore formed an explicit coalition (the Pacific group) for purposes of negotiations concerning this issue and submitted a joint proposal in May 1987. This group's position is closer to that taken by SOE during the Tokyo Round. During 1987, Switzerland, Brazil, and Egypt all supported proposals for the use of domestic measures rather than border protection. The position

50. Although the United States was not extremely concerned with the compensation question during this negotiation, it is the nation that has offered compensation most frequently in the past when invoking Article XIX actions. See Sampson, "Safeguards."

51. Information on the Uruguay Round is based on interviews with and documents supplied by trade policy officials and diplomats. 
of most of the developing countries is similar to that taken by $L D C$ during the Tokyo Round.

Since the issues are identical, the characterization of possible agreements along three dimensions remains relevant to the Uruguay Round. What about the positions? Although the United States formally continues to express a preference for nondiscrimination, it is likely that it will push for some kind of consensual selectivity in the Uruguay Round. According to informal discussions with EC trade officials, the recognition that unilateral selectivity is not in the EC's own interest is emerging. This altered perception may be due to the fact that the EC increasingly has become the target of selective actions itself. It is unlikely, however, that the EC will formally change its position to one of favoring a nondiscrimination requirement. For one thing, the fact that it has already invested so much political capital in this issue will make it difficult to admit that it was "wrong." But in any case, it seems certain that unilateral selectivity is a dead issue. Consensual selectivity has become much more likely, since it makes unilateral selectivity impossible while allowing for flexibility to negotiate bilateral agreements or to impose nondiscriminatory actions. In addition, part of the Japanese bureaucracy is now reported to be in favor of consensual selective actions because this gives it greater internal control over Japanese industries. This group in general favors a managed economy and managed trade. Another group favors Japan's traditional standpoint of nondiscrimination. For the most part, small open economies and developing countries continue to prefer nondiscrimination, and nondiscrimination is explicitly required in both the Pacific group proposal and the Swiss/Brazilian proposal.

What about the relative weights of the three elements of a proposal? For the United States, the relative ranking of attributes in the Uruguay Round appears to be the same as during the Tokyo Round. Relatively strong preconditions are considered to be the most important element, while compensation is regarded as the least important. The EC continues to prefer relatively weak preconditions (to maintain discretion) and puts little weight on compensation. Primary criteria for the EC are to avoid unilateral selective actions by the United States, avoid having to pay explicit compensation, and remain as flexible as possible. For Japan, relatively strong preconditions are again more important than compensation. For the Pacific group, nondiscrimination is considered to be of fundamental importance, followed by preconditions and compensation. Although this ranking also holds true for Switzerland and Brazil, the two countries disagree with each other on the issue of compensation (Switzerland is opposed to compensation), and they disagree with the Pacific group on the proposed remedy (Switzerland and Brazil favor domestic measures to promote adjustment). Most developing countries continue to have the same ranking of attributes as during the Tokyo Round: nondiscrimination is fundamental, followed by compensation and preconditions. 
Nondiscrimination is thus considered crucial by three blocs (the Pacific group, Brazil/Switzerland, and the developing countries), while the position of the "big three" is ambivalent but may be drifting toward consensual selectivity. For these three individual players, two cases must be distinguished, depending on whether consensual selectivity or nondiscrimination is decided. Assume for the moment that all three push for consensual selectivity and that the status quo is $\mathrm{B}^{\prime \prime}$. The problem for the other players, then, is that the status quo is close if not identical to what is best for the EC, and it is also better for the United States and Japan than it was during the Tokyo Round. An agreement such as $A^{\prime \prime}$ might be feasible, however, since this is also somewhat close to $\mathrm{B}^{\prime \prime}$ and thus not too bad for the EC and since Japan and the United States both prefer $A^{\prime \prime}$ to the status quo. For all of the other players, $\mathrm{A}^{\prime \prime}$ is also preferred to the status quo. As noted above for the Tokyo Round, an alternative candidate for the most preferred option by the EC is $\mathrm{D}^{\prime \prime}$, in which the increasing stringency of the preconditions of an agreement are traded off by removing the compensation requirement. $\mathrm{D}^{\prime \prime}$ is better than the status quo for Japan and the United States but is worse than the status quo for the developing countries.

Three conclusions can be drawn: (1) there is ample scope for a club of the big three; (2) there is some scope for a consensus agreement; and (3) there is a problem for the other players because the status quo may be closer to being optimal for the big three in the Uruguay Round than it was during the Tokyo Round. A formalization of the status quo is not in the interests of the players that prefer nondiscrimination. The implication is that there is as much, if not more, need for cross-issue linkage as there was during the Tokyo Round. Attempts to establish linkages will have to be initiated by the players whose preferences are furthest from the status quo.

If the big three all push for nondiscrimination, it is clear that achieving a consensus agreement will not be a problem. For example, even if the EC were to regard an agreement such as $A^{\prime}$ to be too stringent, $B^{\prime}$ should be feasible and would improve on the status quo for all players. If the big three part ways on the issue of selectivity, more interesting situations may develop. For example, if the United States and the EC cannot agree, not only is a consensus agreement unlikely to emerge, but club formation also may not be possible. If they do agree, it is likely that Japan will go along. Linkage in this case will again be required to attain an agreement.

Although it is unlikely that within-issue trade-offs will suffice to foster agreement, there are many possibilities for cross-linkage because the agenda of the Uruguay Round is broad. ${ }^{52}$ The qualitative approach outlined above can be used by analysts, negotiators, and policymakers to determine the scope for agreement. This, in turn, should lead to the identification of linkages to improve mutual gains from trade.

52. For a suggestion that focuses on trading off services and safeguards, see Hoekman, "Services as a Quid Pro Quo." 


\section{Conclusions}

Investigating the potential for cross-issue linkages during MTNs is a productive strategy for participants, especially in cases in which agreement seems unlikely to occur. Determining the need for such linkages requires analysis. Since this analysis often cannot employ quantitative techniques, I have suggested a qualitative approach that identifies like-minded nations (players) and possible proposals (solutions) through a method of comparing the anticipated outcome of proposals to the status quo or no-agreement outcome for each player. This conceptually simple method may not always be easy to apply, but it should give a good indication of what the scope for agreement is and where there is a need for cross-issue linkages. Implementation of a linkage strategy will not be a trivial matter, and there are many procedural questions and problems that have to be addressed..$^{53}$ However, the main problem is substantive, in that there must be a willingness to explore the cross-issue linkage option and deal with the constraints that inhibit linkages from occurring.

Negotiators and relevant policymakers presumably have enough political knowledge and skill to conduct an analysis along the lines set out above. Indeed, to some extent they will have to do something of the sort in order to be able to negotiate at all. While there may be reasons for policymakers to be "rationally ignorant" of procedures that identify the scope for joint gains, this cannot be taken to imply that the recommended analysis is superfluous. Even though analysts can argue along the lines of the public choice literature that what is real is rational, this does not mean that it is impossible to do better. In any event, the "rationally ignorant" policymaker is not the only constraint on exploring possible linkages, since there are also informational and resource constraints, especially on the part of developing countries. Thus, even if we could not prevail upon negotiators and policymakers to undertake this type of analysis, there is certainly a case to be made for independent analysis to help fill the gap.

To a large extent, the constraints that limit the feasibility of cross-issue linkages in MTNs are the same ones that inhibit liberalization of trade policies. Domestic constituents that stand to lose from a change in the status quo tend to have greater political clout than those that stand to gain. The trade policy literature on the political economy of protection argues that the gains from trade need to be incorporated into policy via the greater transparency of the costs to society when intervention in trade occurs. ${ }^{54}$ This line of reasoning is applicable to MTNs as well as to domestic policy formulation. If negotiators are forced to limit themselves primarily to within-issue tradeoffs, not only will potential gains from trade be lost, but import-competing industries will also find it easier to defend existing rents. The result is likely to be detrimental to the multilateral trading system.

53. See Bernard Hoekman, "Developing Country Participation in the Uruguay Round," Discussion Paper no. 225, Research Seminar in International Economics, University of Michigan, Ann Arbor, August 1988.

54. See J. Michael Finger, "Incorporating the Gains from Trade into Policy," The World Economy 5 (December 1982), pp. 367-77; Laird and Sampson, "Case for Evaluating Protection"'; and Bhagwati, Protectionism. 